\title{
The Virtual Sabbatical: A Pioneering Case Study
}

\author{
Patricia Easteal • Nicole Westmarland
}

Published online: 3 July 2010

(C) The Author(s) 2010. This article is published with open access at Springerlink.com

\begin{abstract}
International exchange is an important aspect of academic life. Thus, international sabbaticals are, in general, seen as a measure of research collaboration, networking, and international standing. There are, however, a few groups who are likely to be disadvantaged by such criteria even though they may be implicit, that is, those for whom international travel is problematic. Using reflective learning, the researchers conducted a virtual sabbatical for six months as a metaphorical "ramp" - that is, a way of making international sabbaticals accessible to more people. We now present a case study of this action research project, which answers the following questions. How does the concept of a virtual sabbatical fit holistically within the context of higher education? How can the aims of the sabbatical be fulfilled in a virtual context? What are the problems and successes of the virtual sabbatical?
\end{abstract}

Key words sabbatical $\cdot$ virtual $\cdot$ online technology $\cdot$ action research $\cdot$ case study

Patricia Easteal received her Ph.D and M.A. from the University of Pittsburgh and her B.A. from SUNY Binghamton. She is a Professor of Law at the University of Canberra in Australia. Her research and teaching highlight access to justice issues, particularly the law and violence against women.

Nicole Westmarland is a lecturer in Criminal Justice in the School of Applied Social Sciences at Durham University, United Kingdom. She received her Ph.D. and M.A. from the University of York and her B.Sc. from Teesside University. She researches male violence against women and is currently working on a longitudinal study into the effectiveness of domestic violence perpetrator programmes.

Although the virtual sabbatical is described in this paper as a replacement for international sabbatical, it could be used much more widely. The same factors that preclude international travel may prevent domestic sabbatical relocation. We document a model that is relevant and applicable in that context, too.

P. Easteal $(\bowtie)$

University of Canberra, Canberra, Australian Capital Territory, Australia

e-mail: Patricia.Easteal@canberra.edu.au

N. Westmarland

Durham University, Durham, UK

e-mail: nicole.westmarland@durham.ac.uk 


\section{Background}

International exchange is an important aspect of academic life. An institution of higher education benefits from sabbatical visitors in a number of ways, such as the individuals' contribution to the learning experiences of the student population and the enrichment of academic staff's [faculty members'] ${ }^{1}$ intellectual environment through informal discussion and formal seminar presentations. The visiting academic may develop collaborative relationships with academics at the host institution and set the groundwork for joint research projects, which are advantageous to both host and visitor. The visitor gains intellectual insights, which may enhance research, through informal discussions and by participating in the intellectual life of the host institution.

Thus, international sabbaticals are, in general, perceived as a measure of international collaboration, networking, and standing; these are "esteem" and "productivity" criteria used by many universities and colleges when deciding on promotion and tenure for faculty members. Academics unable to travel internationally may therefore experience reduced promotion prospects, may not be recruited for senior-level positions, and may not have as many opportunities to develop international collaborations that are conducive to coauthored international research grant applications and publications.

Several groups are likely to be disadvantaged by such criteria, which are often implicit rather than explicit. For instance, female academics with children could be constrained in travel choices given their child-caring responsibilities and the challenges surrounding temporary removal of children from schooling. They may have fewer financial resources for international travel with the mean, gross, weekly earnings (ordinary time excluding overtime and other penalty rates) of Australian women lower than that of men across all age groups and occupations. This gender pay gap had increased to 17.5\% in 2009 (ABS 2010). The inequality is even more pronounced for mothers in Australia: women who have a bachelor's degree and two children will earn $\$ 1.8$ million throughout their working life while fathers with the same qualifications and number of children will earn $\$ 3.3$ million (Cassells et al. 2009). A similar gender pay gap has been found in academia (Barbezat and Hughes 2005; Ward 2001). Therefore, the relationship partner who is making more money may be unable or unwilling to relocate for an entire semester, as dictated by a sabbatical's necessary length of time. Aside from women, those who require on-going medical treatment, have a physical disability that affects their ability to travel, have involvement with infertility treatments requiring regular scans, or have health conditions such as agoraphobia would be unable to comply with the implied expectation of venturing far from home.

Individuals and institutions may not recognize that the academic "success" criterion of international travel is discriminatory because it is a measurement of performance applied to academic staff in academia. Plus, that criterion may seem reasonable as workplace conditions are "designed, whether deliberately or unreflectively, around the behaviour patterns and attributes of the historically dominant group in public life" (Rees et al. 2008, p. 122). This illusion of reasonableness is also the case for women and child caregivers with employment conditions requiring long hours, that is, outside the norm of $8-5$ and perhaps early morning and/or evening and weekend work commitments. Historically, these practices have been seen as equally reasonable and applicable to all. In reality, we need to question if

\footnotetext{
${ }^{1}$ For the convenience of readers, common North American language terms are provided in brackets after the first appearance of terms commonly used in Australia.
} 
this is truly the case since a substantially higher proportion of males are able to comply with these kinds of expectations or requirements. These conditions do in fact have a disparate effect on women since working full-time or overtime is far more problematic for them in a cultural context that stresses females' other roles of parent, cook, and cleaner (Easteal 2001). Furthermore, there is case law in Australia that such requirements are not reasonable or necessary. (See, for example, Escobar v Rainbow Printing. (2002); Evans v National Crime Authority. (2003); and Mayer v Australian Nuclear Science and Technology Organisation (2003.).

It is not within the scope of this article to question or discuss the validity of international activity, standing, or reputation as criteria for promotion. For our research project we operated from the assumption that international travel is treated as a reasonable expectation and sometimes a requirement for career academics. Therefore, we asked ourselves some questions. If indeed certain groups are disadvantaged but a particular requirement or expectation is treated as reasonable, what sort of equitable adjustment can institutions of higher education make? Buildings for people in wheelchairs are made accessible by installing ramps. If full-time hours are deemed necessary, workplaces can adopt familyfriendly work practices to allow staff with child-caring responsibilities to complete their work hours within more flexible arrangements. Accordingly, how could sabbatical practices be made more flexible and allow an academic to engage in an international sabbatical without travelling? Since universities and colleges generally desire and value real engagement rather than simply a linking on paper, it is necessary to consider exactly how this real engagement could take place in a virtual context.

We report here on a case study investigating that question, specifically answering the following:

- How does the concept of a virtual sabbatical fit holistically within the context of higher education?

- How can the aims of a sabbatical be fulfilled virtually?

- What are the problems and successes of the virtual sabbatical?

Easteal, an academic in Australia, spent six months as a virtual visiting fellow at Durham University in the United Kingdom. Without physically leaving Australia, she became a visible part of the Durham academic community which shared her research interests. A symbiotic scholarly exchange was facilitated through informal discourse and formal presentations.

\section{Methodology}

We conducted the virtual sabbatical primarily as a participant observer case study. A case study is the appropriate method given Yin's (2009, pp. 7-8) view that the single-case study can be used for any or all of three purposes: exploratory, descriptive, and explanatory. It is also deemed a suitable methodology if the research questions begin with "how" or "why," does not require control of behavioral events, and focuses on contemporary events. We use a holistic (single unit of analysis) design with the rationale that it is a "unique case" (Yin 2009, p. 47).

We also integrated the steps of action research throughout the six-month case study; these steps are reflection, dialogue, and change as described by Wilson and Streatfield (n.d.). Action research correlates well with some of the positive attributes that Yin $(2009$, p.69) identifies as ideal for a case study investigator. These include being adaptive, flexible, sensitive, and responsive to contradictory evidence. 
After applying for and receiving a visiting virtual fellowship from Durham University, the visitor (Easteal) and host (Westmarland) worked with colleagues at their institutions with expertise in communication software. Melbourne University Digital Media Solutions was also consulted. It was necessary to establish which particular resources were available there as the School [College] of Law, University of Melbourne, was to be the site of Easteal's face-to-face sabbatical to be experienced concurrently with the virtual one. In accord with the concept of a virtual sabbatical, all information was exchanged electronically, that is, via audio conference and email correspondence. The learning technology staff consulted all agreed that technology choices must be made in cooperation with the host institution and would be constrained by its tools, i.e., what software was available to relevant staff and students.

We also felt that at least part of the purpose of this initial virtual sabbatical project should be for the researchers and information technology (IT) staff to learn how to use and support the myriad of networking tools available today. Support is an issue because academics and students may have different expectations and experiences in using virtual technologies than do IT staff, who have the expertise, enthusiasm, and time to acquire extensive technical skills.

Project evaluation was built into the methodology. From onset to completion, all aspects of planning and implementation were experiential and used the collaborative, action research project model described above. Thus, assessment was closely intertwined with the reflections of the two researchers (host and visitor), who engaged in on-going critical dialogue with single-loop and double-loop learning (Greenwood 1998). Therefore we made changes based on the difference between expected outcomes and actual results and by questioning the underlying assumptions that had underpinned our action plan.

We also monitored the frequency of hits on the visitor's presentation web site as an indicator of engagement. Westmarland, channeled evaluative verbal and email feedback from those who had communicated in real time with Easteal, and/or listened to pre-recorded online presentations by the visitor. Additionally, Easteal's face-to face sabbatical with the School of Law, University of Melbourne, provided a benchmark to assess the networking, scholarly dynamic, and engagement between herself and the relevant Durham research community.

\section{The Higher Education Virtual Context}

E-learning proliferates around the world, and now individual courses and entire degrees are offered as distance or online learning. In Australia for example, a student interested in studying just about any field - undergraduate or postgraduate [graduate] — can find a university that provides the courses desired either through total distance study or programs integrating e-learning with a face-to-face component (Distance Learning Australia, 2010). Oxford, Massachusetts Institute of Technology, and other major institutions have placed individual lectures online; and many institutions offer entire subjects online. The idea of including talks by virtual visiting lecturers is mentioned as a possibility if one is developing and teaching a subject entirely online with a hypermedia educational module (Radoiu et al. n.d).

The Internet encompasses a plethora of technologies, which educational institutions and educators are using to create new learning environments for students. Examples include the University of Bradford in the UK having developed a digital repository based on open source software for all Masters dissertations and doctoral theses (Guide to Virtual Scholars 2006) and the large-scale Australasian Digital Thesis repository, which acts as a gateway to postgraduate [graduate] research across universities in Australia and New Zealand. However, these 
technologies have not yet been adapted for use by visiting virtual scholars on sabbatical, as far as we know.

We also see programs designed for students to get a taste of what it is like to work in the corporate world through a virtual experience (Radbourne 2004). Reports from interns who have telecommuted to businesses and/or non-profit organisations indicate that the virtual nature of the internship did promote flexibility and personal initiative. However, disadvantages such as less networking and supervision are also mentioned (Landsberg 2010; Thomas-Bailey 2010).

There are examples of virtual connections between and among faculty members, too. For example, Fairleigh Dickinson University offers a global virtual faculty. On their web site it is described as:

... a cadre of distinguished scholars and practitioners from around the world who serve as Global Virtual Faculty members in partnership with the on-campus faculty in teaching of our on-line courses.... The primary role of a GVF member is to bring a global dimension to the learning experience by offering different perspectives and observations to students on the issues under study (Fairleigh Dickinson University n.d.).

The research sphere of academic life has also tapped into virtual communication. Most academic institutions now have virtual libraries. Cyber collaboration and virtual manuscript processing have become normative practices. Virtual conferences are not unusual; see for instance how the History department at State University of New York at Albany designed an entirely electronic conference (Hamm n.d.). Similarly, a virtual psychology centre brings together academics from the United States, United Kingdom, New Zealand, and Australia "jointly working to realise some shared projects within this computer-based medium" (The Virtual Faculty n.d.). These projects include sharing research ideas and staffing post-graduate diploma [degree] courses.

These are just a few examples of how e-communication or Computer-Mediated Communication (CMC), meaning "any communicative transaction which occurs through the use of two or more networked computers" (Computer-mediated Communication 2010), is being used in higher education. Therefore, bringing $21^{\text {st }}$ century technology into universities is not new. Although we could not find a record of a documented virtual sabbatical, the concept would appear to be appropriate in an environment that is increasingly using $\mathrm{CMC}$ in teaching and research-related activities. The benefits of virtualization are not clear to all, however. Field reports are of value in identifying pedagogic or technical issues and encouraging informed exploration that moves beyond the hype evident in literature from e-generation enthusiasts (Bennett et al. 2008).

\section{The Virtual Sabbatical Experience}

We now describe the various actions we undertook in making a virtual sabbatical operational. These included, first, identifying a host institution; second, articulating the aims of the sabbatical; third, exploring possible software and technologies to achieve the goals of the sabbatical via cyber-space; and then last, implementing and practicing the networking and informal and formal communication formats we had selected.

\section{Finding a Host}

Identifying a host institution proved to be slightly challenging for the prospective virtual visitor, Easteal. About eight months before her leave was due to commence, she contacted 
several people, one at a time, whom she already knew and who worked at various universities in the United Kingdom. The first two expressed an interest in the concept; but, perhaps due to busy lives or a prospective individual host's need to clear the way through an administrative bureaucracy for this experience, these contacts did not come to fruition. The third person (Nicole Westmarland) responded positively and quickly sought approval for this arrangement from Durham University's Board of Studies. This process involved sharing Easteal's curriculum vitae and ideas relating to how the virtual aspects of the sabbatical would be conducted. The Board of Studies then nominated Easteal as a Visiting Fellow to the Faculty Pro-Vice Chancellor, who approved her appointment and formally reported to the University Senate.

Neither academic (host or visitor) had previously worked together on a research project, nor had they met each other in person although they were engaged in a joint book project.

\section{Establishing the Aims of the Sabbatical}

The next step of the virtual sabbatical process was to identify how the aims of the sabbatical might be accomplished in cyberspace. Through reflection and discussion, Easteal and Westmarland developed Table I, which outlined the goals of sabbatical, how they are

Table I Goals of Sabbaticals, Face-To-Face and Virtual Means of Achieving Them

\begin{tabular}{|c|c|c|}
\hline Goals & Face-to-face & Ideas for virtual \\
\hline \multirow[t]{3}{*}{$\begin{array}{l}\text { Visitor becomes a visible } \\
\text { part of the host community }\end{array}$} & Visitor is introduced to staff & $\begin{array}{l}\text { Introduction via email, } \\
\text { videocast and a blog }\end{array}$ \\
\hline & $\begin{array}{l}\text { Visitor attends seminars, } \\
\text { meetings, morning } \\
\text { teas/coffee }\end{array}$ & $\begin{array}{l}\text { Virtual attendance at } \\
\text { meetings (either live } \\
\text { or recorded) }\end{array}$ \\
\hline & & $\begin{array}{l}\text { Virtual one-on-one } \\
\text { interaction using email } \\
\text { and conferencing }\end{array}$ \\
\hline \multirow[t]{2}{*}{$\begin{array}{l}\text { Visitor builds collaborative } \\
\text { social and research networks } \\
\text { with host academics }\end{array}$} & $\begin{array}{l}\text { Informal talks which result } \\
\text { in identifying areas of } \\
\text { mutual interest. }\end{array}$ & $\begin{array}{l}\text { Informal talks at set time } \\
\text { using conferencing software }\end{array}$ \\
\hline & & $\begin{array}{l}\text { CV distributed to all staff via } \\
\text { email Dialogue with persons } \\
\text { who have mutual interests via } \\
\text { email, LinkedIn, Facebook, } \\
\text { and blogging }\end{array}$ \\
\hline \multirow{2}{*}{$\begin{array}{l}\text { Visitor contributes to the } \\
\text { scholarly culture of the host } \\
\text { institution and individuals' } \\
\text { research }\end{array}$} & Visitor gives seminars & $\begin{array}{l}\text { Visitor gives seminars (live or } \\
\text { recorded; video or audio) }\end{array}$ \\
\hline & $\begin{array}{l}\text { Visitor has informal } \\
\text { discussions with host } \\
\text { academics, e.g. over a } \\
\text { meal or in the hallway. }\end{array}$ & $\begin{array}{l}\text { Informal discussions (focused } \\
\text { blogs, discussion boards, other) }\end{array}$ \\
\hline \multirow{4}{*}{$\begin{array}{l}\text { Visitor enhances her own } \\
\text { scholarly range and uses } \\
\text { host resources to contribute } \\
\text { to her research }\end{array}$} & Visitor attends seminars & Informal discussions as above \\
\hline & $\begin{array}{l}\text { Visitor engages in informal } \\
\text { intellectual discourse }\end{array}$ & Recorded meetings sent to visitor \\
\hline & & Blogging \\
\hline & & Emails \\
\hline
\end{tabular}


generally met in face-to-face sabbaticals, and ideas for how to achieve those goals virtually. As the Table illustrates, these include becoming a part of the host community, contributing both to its scholarly culture and to the visitor's and host staff's scholarly range and research, and building collaborative ties.

\section{Exploring Possible Software and Technologies}

Before making concrete decisions about which technologies to use, we consulted with IT specialists, researched possible software options, and reflected on the fit of the different types of communication within the context of this particular sabbatical. This was an essential stage in the virtual sabbatical case study. Following is a brief summary of what we learned.

For Networking IT colleagues suggested that the social networking web site Linked in (2010) could be a useful way for the visitor to network with host colleagues. To create a stronger sense of connection, if the host institution "yammered", Easteal could be given a temporary email address at the host institution, thus joining the host institution's network. A yammer network enables people within an institution to twitter (micro blog) amongst themselves and can expose a virtual visitor to the culture of a host organization (Yammer 2010). Another path conducive to networking is blogging, with tools such as Blogger (2010). Also, the visitor can be added to the appropriate emailing lists for the sabbatical period.

For Meetings For video conferencing between the visitor and the staff at Durham, we determined that Skype (2010) or iChat (2010) for Macs were both free and easily uploaded. Alternatively, cyber-conferencing facilities were available at a cost at both Durham and Melbourne University. The IT staff suggested that XMeeting (2007) or Mirial (2010) desktop conferencing software would facilitate visitor attendance at school or centre meetings in real time. Neither would be free but could be uploaded onto Easteal's computer at no cost for a 30-day trial period. For asynchronous involvement, the meetings could be recorded using a digital recorder, or Flip (2010) camcorder technology for producing and screening allows inclusion of a visual element. Easteal could listen to and/or watch the meeting and email any ideas or feedback on topics discussed.

For Formal Presentations We learned that our major choice here was transmission live over the Web (synchronous), which allows for two-way interaction, or pre-recorded presentations (asynchronous) such as webcasting, in which data transmission is delivered in one direction, disallowing immediate interaction between the presenter and their audience. For both styles of virtual interaction we found that there is no lack of technology, and a large number of software packages suited our objectives.

Software like Elluminate (2010) to project PowerPoint slides and voice synchronously could be used for live streaming, which is also referred to as webinar (abbreviation for a Web-based presentation) in technological circles. Elluminate would also allow for other types of idea and information exchange such as videoconferencing, virtual whiteboard, and file sharing. Alternatively, a standard video-conferencing kit could be used.

We learned too that if we chose to use a real time interactive webinar, we needed to decide whether to use visual presentation, that is, a "talking head", or simply to use audio and PowerPoint. Durham's IT specialist felt there could be benefit in having Easteal's head at the beginning of the videocast and for questions but stated that "it could be distracting during the rest of the presentation, so voice and slides might be better suited (and less vulnerable to network performance issues)." 
To produce asynchronous seminars and teaching presentations, we identified Voicethreads technology as a definite possibility. Voicethreads is described as "a collaborative, multimedia slide show that holds images, documents and videos, and allows people to navigate pages and leave comments in 5 ways - using voice (with a microphone or telephone), text, audio file, or video (via a webcam)" (Voicethread 2010). An alternative was a software package such as Slideshare (2009), which allows for PowerPoint presentations to be shared. Other asynchronous software programs suggested for Mac users included Apple Podcast Producer (Apple 2010) and ScreenFlow, "a professional screencasting studio" (Telestream 2010), which integrates slides, audio, and a "talking head." We further established that pre-recorded presentations could be uploaded onto YouTube (2010) or podcasted with Vimeo (2010).

\section{Deciding on How Best to Network and Effectuate Scholarly Exchange}

In the next stage of the case study, choices needed to be made about real time versus prerecorded delivery, and then the specific modes of communication and appropriate corresponding software technologies could be selected. (See Table II)

Table II Sabbatical Plan and Itinerary

\begin{tabular}{|c|c|c|}
\hline Date (2009) & What & How \\
\hline By mid-July & Finalize plan for virtual activities & $\begin{array}{l}\text { Discuss with IT staff. } \\
\text { host and visitor regularly Skype. }\end{array}$ \\
\hline By mid- August & Introduce visitor to host institution & $\begin{array}{l}\text { Send out CV plus description } \\
\text { of the sabbatical to relevant } \\
\text { staff via email } \\
\text { Produce and post introductory } \\
\text { videocast } \\
\text { Alert relevant Schools and } \\
\text { Centre to visitor's videocast, } \\
\text { blog, LinkedIn site, formal } \\
\text { presentation(s), and regular } \\
\text { morning coffees }\end{array}$ \\
\hline By mid- August & Implement informal discussion groups & $\begin{array}{l}\text { Tuesday } 9 \text { a.m., Skype morning } \\
\text { coffees. Use agreeAdate } \\
\text { (http://www.agreeadate.com/) } \\
\text { to set up. } \\
\text { Start blogging, updating LinkedIn, } \\
\text { and emailing }\end{array}$ \\
\hline August-December & $\begin{array}{l}\text { Have visitor attend meeting of group } \\
\text { discussing violence and abuse research }\end{array}$ & $\begin{array}{l}\text { Use software that allows for live } \\
\text { attendance or record meetings }\end{array}$ \\
\hline October-November & Visitor gives three presentations & $\begin{array}{l}\text { Use ScreenFlow to make one } \\
\text { audiocast and two videocasts } \\
\text { Post on Vimeo site }\end{array}$ \\
\hline Entire time period & Feedback/critical reflection & $\begin{array}{l}\text { Visitor and host engage in on-going } \\
\text { dialogue } \\
\text { Email and informal comments from } \\
\text { staff who participate }\end{array}$ \\
\hline
\end{tabular}


The following variables influenced our decision-making:

- Host experiences, software practices, and availability of conferencing rooms. For instance, Westmarland and her colleagues did not routinely Twitter or Yammer.

- Location of Durham's videoconferencing rooms. There were none located in close physical proximity to Westmarland's School building.

- Time differences between England and Australia. There was a nine hour time difference at the commencement of the sabbatical: $5 \mathrm{p} . \mathrm{m}$. in the UK equated to $2 \mathrm{a} . \mathrm{m}$. on the east coast of Australia from July-October, and then 4 a.m. after clocks changed for daylight savings time in the UK.

- The host's standard seminar program time and meeting times. School of Applied Social Science seminars were routinely scheduled for 5 p.m. (GMT), and meetings of the violence against women research group, usually happened over lunch-12-1.30 p.m. (GMT).

- The host's social interaction dynamic. There was no regular morning/afternoon coffee ritual.

- Skills and knowledge of those involved. The visitor's e-communication experiences were narrow and only included email, Skype, iChat, and Facebook.

Networking/Informal Communication The virtual visitor set up a blog and also joined Linked in (2010) as a potential pathway of communication. She was already on Facebook and Skype, as was Westmarland.

We decided that the visitor would send a short test video, (Easteal 2009), which would serve to introduce her to people who were at the University during the summer. This would be the equivalent to Westmarland taking Easteal to colleagues' offices and making introductions if the sabbatical were performed in the usual face-to-face format. We chose to try ScreenFlow as the software for making this video and Vimeo for its screenings. These packages were chosen by trial and seemed to be the most user-friendly, allowing an inexperienced person like Easteal to record, edit, and then export an mp4 downloaded version of the talk.

Easteal was not added to the host university email since Westmarland did not see it as an integral part of a sabbatical and considered most of the e-mails she had received and read during her own face-to-face sabbatical the previous year as irrelevant to her research engagement with the department which she was visiting. As far as email focusing on connecting the visitor to the host community, with non-virtual scholars Durham School of Applied Social Sciences usually sends out two: the first to introduce the visitor and provide contact details and a second to announce the time and date of the seminar that the visitor would present. Given her concern that academics might rapidly disengage if inundated with lots of group email, Westmarland sent one email about Easteal's sabbatical. In this message, she sent the link of the introductory video to a targeted number of staff in the School of Applied Social Sciences and to members of GLAD (Gender and Law at Durham) encouraging those colleagues, whom she had identified as sharing in Easteal's research interests, to have a look at the video and advising them about opportunities to interact with the visitor.

Since we also wanted there to be synchronous communication, we decided on fortnightly morning coffees using Skype. The first meeting took place on 18 August, 2009. Due to an unexpected firewall, Easteal had to Skype out to Westmarland's office telephone (that is, call the landline phone from her computer's Skype program), and had an interesting conversation with one academic about new practices in UK universities 
requiring probationary academics to get a postgraduate certificate in education. Other morning coffees throughout the semester were facilitated either with a laptop at Westmarland's office or in one case the researcher chatted with Easteal while eating her breakfast at home.

Aside from these interactions, we thought that it would be appropriate for the visitor to attend a meeting of GLAD via video conferencing. Melbourne University IT helped Easteal to download XMeeting (2007) and Mirial (2010). Durham had just acquired new conferencing facilities, and the IT staff was eager to try a link-up. As discussed below, the technology failed on this occasion. Consequently, Westmarland recorded the next meeting of the group using a Flip video camcorder and sent a link to Easteal with FLIP private video showing (Flip 2010).

Formal Presentations Given the time difference and the location of videoconferencing facilities at the host institution, we chose to make formal presentations asynchronous.

Recording the first talk was effectively action learning, with numerous rehearsals necessary for a successful final outcome. Easteal needed to learn how to make eye contact with the camera, leave space on slides for the image of her head, and to talk to a screen instead of a live audience. She then needed to edit the clip, particularly because she wanted to move the talking head in and out of the presentation. Fortunately, ScreenFlow is designed for amateur users and is very user-friendly. It was also beneficial to have IT support easily available via email interaction.

The second pre-recorded talk was an audio podcast combined with separate electronic Word attachments, which were posted on Durham's blackboard. The web site address and an email address for hardcopies were emailed on October 26, 2009, to all staff and visitors at Durham via a monthly newsletter sent out by central administration. In recording this talk, Easteal inadvertently discovered how to record audio tracks since without PowerPoint slides it was easier to speak in segments. The tricky part of the operation-merging several tracks into one track-was not difficult, but challenging since it was the first time she had done this.

The third recording was longer, about 45 minutes, and provided Easteal with yet another learning experience. When exporting the ScreenFlow file into an Mp4 file format, she realized that she needed to know her computer's memory requirements. In attempting to export the talk, the export froze midway through several times. An IT expert came to the rescue after Easteal sent out an urgent email asking for help. The technician suggested exporting the file as an iPhone file instead of an iPod file since it is a smaller format and requires less memory. This proved to be a successful solution to the issue. This videocast was shown at a normal staff seminar in the usual venue, followed by a discussion.

The fourth presentation, approximately 50 minutes in length, was saved as an iPhone file and then posted on Vimeo. This talk was not used as a seminar; instead, interested staff, postgraduate students, and undergraduate criminal law students were sent the hyperlink.

\section{Problems and Successes}

Technology

Our reflective analysis revealed some glitches, primarily technological, which could be easily dealt with by future cyber-scholars on sabbatical. Our recommendations follow. 
It is important to choose software carefully. There were a few issues with FLIP, the primary one being a required lengthy buffering time of about an hour. (This is the amount of time required for the video file data to be downloaded from the Internet and stored in the computer's memory.) This was not immediately apparent. Once buffered, the quality of the video was excellent; but the audio was problematic, probably due to the physical layout of the meeting and distance of speakers to the microphone.

Choosing the software means one should also learn about its limits. In using Skype for visual conferencing we discovered that if more than two computers are used, the broadband Internet bandwidth does not allow for video conferencing. This knowledge helped us construct our method for informal discussion. We also found that Skype would not function between Westmarland's university desktop computer and the laptop that Easteal was using, possibly due to a university firewall. Therefore, one must become aware of firewalls.

A rehearsal hook-up is advised, preferably a couple of days ahead of time, as opposed to half an hour ahead as we did. Then there will be ample time to investigate and develop alternative options if there are any technological hitches. However, both because of prior commitments and as a result of the time difference, Westmarland's time limitations were a barrier to conducting a rehearsal this far ahead of time. For these reasons we were unable to have a run-through with the technology for the synchronous meeting. Potentially the connection was not successful because of the newness of the technology at Durham and the lack of technical expertise on-site. As a fallback we then tried to use Skype's video-chat function, but the microphone on the computer was not strong enough; and Easteal could not hear what the meeting attendees were saying.

Also, one must be prepared to feel overwhelmed by technological choices. As stated earlier, there is no lack of suitable software; in fact, the opposite is true. We found that universities' IT teams are, however, very positive about supporting virtual scholars, perhaps in anticipation of their own staff embarking on similar journeys and tapping into their institutional IT resources. There is a substantial potential demand since academics employed in Australian universities and active in research are eligible to apply for one semester sabbatical leave every 3 years.

\section{Time}

The host's time limitations in commitment and the geographical time difference may be problematic. In our experience, a virtual sabbatical requires more preparation and more advanced dialogue between host and visitor than does a traditional sabbatical. Although this means more time invested for the host, it also infers the experience could result in a far more planned and shared experience. Westmarland does regard the virtual sabbatical as something that was good to try, but feels that the implications of the time difference between Australia and the UK were not thought through carefully enough. She would be wary of doing a project again that involved such a large time difference.

At an early stage of our exploration the Durham's IT expert whom we consulted had pointed out that the role of the individual host in the virtual context would be extremely important in facilitating connection with the host community:

The critical success factor will be the level, frequency and depth of engagement you manage to achieve with staff from the host department, given that like any sabbatical visitor you are competing for time in their already busy diaries. You have the added problem of not physically being there, and so are much more reliant on the actions of your local contact-who acts as an ambassador/envoy for you. 
In her face-to-face sabbatical at Melbourne University, Easteal's individual sponsor did not need to make any arrangements or act as a liaison. A Faculty of Law administrator arranged for her to be networked on email lists, which provided information about seminars and colloquia. Easteal then attended the events of her choosing and gave two presentations by invitation from the two seminar program co-ordinators..

In contrast, Westmarland coordinated all the hosting tasks at Durham. These included arranging for a position as visiting fellow from the central administration, collaborating with the IT services at her university, introducing the visitor to relevant departments or centres, encouraging colleagues to have morning coffee with the visitor, setting up the seminar presentations, and recording a couple of meetings. Accordingly Westmarland found the project took more of her time than initially envisaged; and, as she was not on sabbatical herself, completing these tasks was difficult. It could be more advantageous therefore for two academics, both of whom have been awarded sabbatical leave, to do a cyber exchange, so that each person has enough time to devote to the experience.

\section{Engagement}

Engagement by Durham staff was more limited than we had hoped for; no one visited Easteal's sabbatical blog, nor did any of the Durham staff become members of LinkedIn. However, when compared with the concurrent face-to-face sabbatical, there was as much or even more engagement. The low number of people seeking a meeting with the visitor was not necessarily a reflection of the virtual context of discourse. Academics are busy people; and, unless morning tea is an entrenched ritual within an institution, one could expect a fairly low response. Also, because of the time difference, morning coffee (or tea) had to be quite early, at 9 a.m. for the UK academics. This proved to be restrictive.

The introductory videocast had 44 hits while the audio presentation (on innovative ways of teaching law) had been listened to 22 times by December 31, 2009. The potential audiences included 25 members of GLAD; some of these were among the 16 sociologists in the School of Applied Social Sciences and the 37 academics in Law.

After viewing the first presentation, Westmarland suggested that Easteal's talking head should be on the screen for longer in future videocasts as it provided a more personal connection for the viewer. Perhaps that advice and its adoption contributed to positive feedback on the third videocast that was run as a seminar. The technology reportedly worked well and was "perfectly clear."

The seminar was incredibly well received by all in attendance, specifically in relation to combating Violence Against Women myths through our own research. The participants felt that it is vital to have an action or policy focus in research to promote radical transformation, both socially and legally. (Chair of seminar)

In a similar vein, the co-convener of the research group who sent the hyperlink for the fourth talk to a cohort of students and staff commented that, "This is great and works so well." She added:

I've had very positive feedback both on your battered women presentation and the one you did in SASS on using law for activism. The feedback I've had is that people were surprised at how useful and helpful the seminars were (in terms of technology, not you and the content). That is, they had much lower expectations of what they'd expect from a "virtual seminar." Your use of the PowerPoints and image worked very well and was well received. 
Two masters students, in particular, who are doing projects on defenses for battered women, found your presentation very useful (here, talking content wise) in terms of material, sources and ideas. (Co-Convenor of Gender \& Law at Durham)

\section{Conclusion}

As we prepared for the pilot virtual sabbatical, there were some colleagues who openly disparaged the quality of e-relationships or conferences. The implication of this attitude is that meaningful connections are unlikely with e-communication. This mindset is no doubt formed from their assumptions and experiences, creating a quasi tunnel vision - the same sort of tunnel vision that evokes comments made by some like the following: "Yes, this world-wide web thing is all well and good, but it will never replace libraries and books."

Being mindful of this perspective, we did not undertake this project with the intention of advocating it as a replacement model for old-fashioned sabbaticals. We were simply testing its efficacy as an alternative for those disadvantaged professionally by their inability to travel internationally.

Easteal regards the online-based virtual sabbatical as an empowering experience as it challenged her to engage in technology outside of her normal comfort zone. She now has the ability to make and transmit her own audiovisual presentations. She and Westmarland gained intellectually through informal discussions and by one-on-one email interchange. For instance, Easteal's grant writing and understanding of specific qualitative research methodology were assisted by learning about Westmarland's work with a particular software package. Westmarland received some tips from Easteal on how to break her Ph.D. thesis into several publications. These informal modes of discourse provided information and acted as a catalyst to engaging the grey matter, which is about commensurate with what Easteal gained from attending several faculty seminars during her concurrent face-to-face sabbatical. Thus, she feels networked to Westmarland and to several people in the Durham academic community on an equivalent level to relationships formed during her real space sabbatical at Melbourne University.

The host institution also gained from the planned scholarly interchange. The value of the virtual sabbatical to segments of Durham's academic community is evidenced by the number of hits on the visitor's presentations and in qualitative comments indicating that the technology worked well and was "perfectly clear". Individuals felt they had benefitted from seminars and/or synchronous dialogue.

Through identifying these successes and problem and our planning and experiences, we hope that these findings can serve as a guide or template for those who would like to conduct their sabbatical in cyber-space. The establishment of virtual sabbatical programs could prove to be a modern and timely way of addressing the needs of members of those marginalised or disadvantaged groups who are unable to travel through real space to interact and collaborate with colleagues in other geographical locations. A cyber scholar on sabbatical does not require office space, a computer or telephone (although we found they did need to be covered by the host institution's insurance). A virtual visit gives more flexibility to the worker, which may be another issue for those juggling research and family responsibilities. Plus, international air travel is less "green" or carbon-friendly than travelling in cyber-space. It is cheaper, too, which is perhaps particularly relevant in times of funding cuts in higher education. 
Acknowledgements We extend our thanks to the personnel with expertise in cyber technology whom we consulted: Dr Malcolm Murray Learning Technologies Team Leader, Durham University (see his profile and site at http://www.linkedin.com/in/malkie); University of Canberra Michael DePercy, who lists his favourite cyber communication tools at www.unhub.com/madepercy; and Ben Loveridge from Digital Media Solutions, University of Melbourne. Thank you also to the three reviewers of this manuscript, the editors, and to Jesse Somer and Bruce Arnold for their invaluable feedback on various iterations of the manuscript.

Open Access This article is distributed under the terms of the Creative Commons Attribution Noncommercial License which permits any noncommercial use, distribution, and reproduction in any medium, provided the original author(s) and source are credited.

\section{References}

ABS (2010). ABS Labour Price Index Publication (Cat. No. 6345.0). Retrieved May 3, 2010, from http:// www.abs.gov.au/ausstats/abs@.nsf/mf/6345.0/

Apple (2010). Retrieved February 1, 2010, from http://seminars.apple.com/seminarsonline/podcast producer/apple/

Barbezat, D., \& Hughes, J. (2005). Salary structure effects and the gender pay gap in academia. Research in Higher Education, 46(6), 621-640.

Bennett, S., Maton, K., \& Kervin, L. (2008). The digital natives debate: a critical review of the evidence. British Journal of Educational Technology, 39(5), 775-786.

Blogger (2010). Retrieved May 1, 2010, from http://www.blogger.com

Cassells, R. Miranti, R. Nepal B., \& Tanton, R. (2009). She works hard for the money. Canberra: AMP and NATSEM. Retrieved May 31, 2010, from https:/www.amp.com.au/wps/portal/au/AMPAUMiniSite3C? vigurl $=\% 2$ Fvgn-ext-templating $\% 2 F v \% 2 F i n d e x . j s p \% 3 F v g n e x t o i d=67 c 93 e 8 b 696 f 1210$ VgnVCM10000083d20 d0aRCRD

Computer-mediated Communication. (2010). Retrieved April 30, 2010, from http://en.wikipedia.org/wiki/ Computer-mediated_communication

Distance Learning Australia. (2010). Retrieved May 1, 2010, from http://www.australian-universities.com/ distance-learning/

Easteal, P. (2001). A kaleidoscope view of law and culture: the Australian Sex Discrimination Act 1984. International Journal of the Sociology of Law, 29(1), 51-73.

Easteal, P. (Presenter and Producer). (2009, August 13). Introduction Virtual Sabbatical [Podcast video]. Retrieved May 3, 2010, from http://vimeo.com/6075957

Elluminate (2010). Retrieved May 1, 2010, from http://www.elluminate.com/

Escobar v Rainbow Printing Pty Ltd No 160. (FMCA. July 30, 2002). Retrieved May 31, 2010, from http:// www.austlii.edu.au/au/cases/cth/FMCA/2002/160.html

Evans v National Crime Authority No 375. (FMCA September 5, 2003). Retrieved May 31, 2010, from http:/www.austlii.edu.au/au/cases/cth/FMCA/2003/375.html

Fairleigh Dickinson University (n.d.) Retrieved May 1, 2010, from http://globallearning.fdu.edu/gvf.php

Flip (2010). Retrieved April 29, 2010, from http:/www.theflip.com/en-au/

Greenwood, J. (1998). The role of reflection in single and double loop learning. Journal of Advanced Nursing, 27(5), 1048-1053.

Guide to Virtual Scholars (2006). Retrieved April 28, 2010, from http://www.brad.ac.uk/library/documents/ virtualscholars.pdf

Hamm, R. (n.d.) Writing history / writing fiction: a virtual conference session. Retrieved April 29, 2010, from http://www.albany.edu/history/hist_fict/home.htm

Ichat (2010). Retrieved May 1, 2010, from http://www.apple.com/macosx/what-is-macosx/ichat.html

Landsberg, A. (2010, April 23). An intern view on virtual internships. Message posted to http:// eyeoftheintern.wordpress.com/2010/04/23/an-intern-view-on-virtual-internships/

Linked in (2010). Retrieved May 2, 2010, from http://www.linkedin.com/

Mayer v Australian Nuclear Science and Technology Organisation No 209. (FMCA. August 6, 2003). Retrieved May 31, 2010, from http:/www.austlii.edu.au/au/cases/cth/FMCA/2003/209.html

Mirial (2010). Retrieved May 2, 2010, from http://www.mirial.com/

Radbourne, J. (2004). An innovation in access: developing the generic skills of business students through a virtual corporate experience. Educational Innovation in Economics and Business, 9, 157-177. 
Radoiu, D. Rotariu, E. and Enachescu, C. (n.d.) Trends in distance education: hypermedia educational modules,' Retrieved May 31, 2010 from http://rilw.itim-cj.ro/97/Radoiu.html

Rees, N., Lindsay, K., \& Rice, S. (2008). Australian anti-discrimination law. Sydney, Australia: Federation Press.

Slideshare (2009). Retrieved April 28, 2010, from http://www.slideshare.net/

Skype (2010). Retrieved May 1, 2010 , from http://www.skype.com/int1/en/features/

Telestream (2010). Retrieved February 2, 2010, from http://www.telestream.net/screen-flow/overview.htm

The Virtual Faculty (n.d) Retrieved May 4, 2010, from http://www.massey.ac.nz/ alock/virtual/welcome.htm

Thomas-Bailey, C. (2010, January 16). Virtual internships: get on by logging on. The Guardian. Retrieved April 28, 2010, from <http://www.guardian.co.uk/money/2010/jan/16/virtual-internships-log-on

Vimeo (2010). Retrieved May 1, 2010, from http://vimeo.com/

Voicethread (2010). Retrieved May 1, 2010, from http://voicethread.com/about/

Ward, M. (2001). The gender salary gap in British academia. Applied Economics, 33(13), 1169-1681.

Wilson T. D., \& Streatfield D. R. (n.d.) Action research and users' needs. Retrieved January 10, 2010, from http://informationr.net/tdw/publ/papers/action81.html

Xmeeting (2007). Retrieved May 3, 2010, from http://xmeeting.sourceforge.net/pages/index.php

Yammer (2010). Retrieved May 2, 2010, from https://www.yammer.com/

Yin, R. (2009). Case study research: Design and methods. Thousand Oaks, CA: Sage Publications.

YouTube (2010). Retrieved May 2, 2010, from http://www.youtube.com/ 